Gazi University
Journal of Science
http://dergipark.gov.tr/gujs

\title{
Optimization of Thermal and Rheological Properties of HDPE-Organoclay Composite Using Response Surface Methodology
}

\author{
Abdallah Mohamed YASSIN ${ }^{1}$ (D) Ebru GUNISTER $^{2 *}$ (D) \\ ${ }^{1}$ Khalifa University, Department of Mechanical Engineering, 127788, Abu Dhabi, UAE \\ ${ }^{2}$ Istanbul Galata University, Department of Basic Sciences, Istanbul, Turkey
}

\section{Highlights}

- The effect of organoclay amount on enhancing the thermal properties of HDPE is significant.

- Mixing temperature is the only linear factor affecting the rheological properties significantly.

- Optimum melt blending processing parameters were predicted for HDPE-Organoclay composites.

\begin{tabular}{l} 
Article Info \\
\hline \\
Received: 01 Mar 2021 \\
Accepted: 24 Jan 2022 \\
Keywords \\
\hline HDPE \\
Organoclay \\
Polymer Composites \\
RSM \\
Thermal Properties
\end{tabular}

\begin{abstract}
The processing parameters to disperse active filler within a polymer matrix to enhance the polymers' properties should be selected carefully to achieve the best dispersion. In this research, Box-Behnken Design (BBD), an experimental design for response surface methodology (RSM), with three levels was used as a design of experiment (DOE) to analyze the effect of processing parameters on the thermal and rheological properties of high-density polyethylene-organoclay (HDPE-OC) composites prepared by adding organoclay (OC) to high density polyethylene (HDPE) using melt blending method. HDPE-OC composites were characterized morphologically by SEM and XRD, and thermally by DSC and TGA, and tested rheologically. Investigated factors were filler amount, mixing temperature and screw speed. The evaluated responses were melting temperature, degradation temperature, storage modulus, and complex viscosity of HDPE-OC composites. The effect of each factor on the responses was determined through an analysis of variance (ANOVA). The obtained data was used to predict the responses by fitting into a second order equation with MINITAB software. Constructed models were verified using validation experiments therefore optimum melt blending processing parameters obtained as $1.5 \mathrm{wt} \% \mathrm{of}$ OC, mixing temperature of $183{ }^{\circ} \mathrm{C}$, and screw speed of $77 \mathrm{rpm}$ for HDPE-OC composites.
\end{abstract}

\section{INTRODUCTION}

Researchers have been extensively studying polymer nanocomposites due to their interests in the controllable properties of polymers with the addition of nanofillers since the 1990s [1-4]. Polymer nanocomposite can be defined as the mixture of a large amount of polymer and a low amount of nanofiller. Nanofillers are additives with at least one of their dimensions less than $100 \mathrm{~nm}$ [5]. Clay, "a naturally occurring material composed primarily of fine-grained minerals", has been used for decades as nanofiller due to its high aspect ratio and low cost. The most used clay type in polymer nanocomposites reinforcement is the montmorillonite (MMT). MMT consists of two types of layers, tetrahedral and octahedral. Tetrahedral silica layers can interact more easily with polymers as compared to octahedral alumina layers [6]. The fact that, clays are hydrophilic whereas the polymers are hydrophobic or organophilic, makes the interaction between them difficult [3,5-10]. To overcome this issue and make clay more compatible with the polymer matrix, an ion-exchange reaction is usually done on the surface of clay particles, which converts the negatively charged clay from hydrophilic to organophilic. The process is done using a cationic surfactant such as quaternary alkylammonium or alkylphosphonium compounds and the modified clay is called organoclay (OC) [6,7]. Polyethylene (PE) is a petroleum based synthetic polymer, and it can be processed in different structures as linear, branched, or crosslinked, which affects its density. High density polyethylene (HDPE) has high tensile strength and high intermolecular force due to its linear structure and 
low branching degree. Because of its unique properties such as being durable and inexpensive as well as its processability, HDPE has various industrial applications [11]. Like most polymers, standing by itself, the properties of neat PE are not sufficient for all industrial applications [12]. It is believed that the better interaction between the polymer and filler, the better the enhancements will be in polymer properties. However, one of the most well-known challenges in preparing polymer nanocomposite is to achieve a good dispersion of filler inside the polymer matrix [1,3,5,13]. Many mixing methods for polymers and fillers have been proposed by different articles to overcome this problem, such as using compatibilizer, modifying the polymer or modifying the filler for better interaction between the filler and host matrix $[3,5,7,14]$. Nevertheless, utilizing an extra compatibilizer to enhance the composite properties is insufficient because of the additional cost needed for such a method. Furthermore, a decrease in the tensile modulus of HDPE layered silicate composite was reported in one study. Such a drop is believed to be because of the plasticizing effect that the addition of compatibilizer has caused [15]. Poor dispersion will be observed if a low temperature is be used in the composite preparation process, as the nano-filler cannot disperse and flow smoothly inside the polymer. Furthermore, when the processing temperature reaches high values, the polymer can degrade, and it can cause defects in the polymer matrix [16]. On the other hand, selecting the optimum processing parameters can lead to better dispersion of nanofiller in the polymer matrix; hence better properties can be achieved. Several studies carried out on the HDPE-filler composite focused on changing only the filler content to study the change in thermal [17-19], and rheological [20,21] properties of HDPE. To this end, the possibility of obtaining better dispersion of the filler by changing preparation parameters such as filler content, mixing temperature and screw speed is yet to be investigated.

This study investigates the effect of processing parameters on the thermal and rheological properties of high density polyethylene - organoclay (HDPE-OC) composites. HDPE-OC composites were prepared using the melt blending method. Design of Experiments (DOE) was utilized to perform the investigation in which factors (filler content, composite mixing temperature, and screw speed) are more significant on thermal and rheological properties of composites. The responses were evaluated as the melting temperature $\left(\mathrm{T}_{\mathrm{m}}\right)$, crystallinity temperature $\left(\mathrm{T}_{\mathrm{c}}\right)$, degree of crystallinity $\left(\mathrm{X}_{\mathrm{c}}\right)$, degradation temperature corresponding to $10 \%$ weight loss $\left(\mathrm{T}_{0.9}\right)$, storage modulus $\left(\mathrm{G}^{\prime}\right)$ and complex viscosity $\left(\Pi^{*}\right)$. Finally, optimum preparation parameters were proposed for HDPE-OC composites.

\section{EXPERIMENTAL}

\subsection{Materials}

The composite materials were prepared using high density polyethylene (HDPE) and organoclay (OC) which is modified clay with a cationic surfactant. HDPE (BB2588) pellets with a density of $0.958 \mathrm{~g} / \mathrm{cm}^{3}$, melt flow rate (MFR): $1 \mathrm{~g} / 10 \mathrm{~min}, \mathrm{~T}_{\mathrm{m}}: 132{ }^{\circ} \mathrm{C}$ and $\mathrm{T}_{\mathrm{c}}: 120.5{ }^{\circ} \mathrm{C}$ were supplied by BOROUGE, UAE [22]. Ca-montmorillonite type of clay collected from north-west part of Turkey and then treated with $4 \%$ w/v $\mathrm{NaHCO}_{3}$ to increase the cation exchange capacity and called as Na-MMT. Na-MMT was modified with cationic surfactant octadecyl trimethylammonium bromide (ODTABr) to change hydrophilic clay particles to organophilic to increase the possibility of the interaction of HDPE and clay particles [7]. The basal space between Na-MMT clay layers was extended from $12.98 \AA$ to $22.06 \AA$.

\subsection{Preparations of HDPE-OC Composites}

HDPE-OC composites were prepared by melt blending method using mini compounder machine with corotating screws, Thermo Scientific ${ }^{\mathrm{TM}} \mathrm{HAAKE}^{\mathrm{TM}}$ MiniLab. To unsure better blending of the composite, in each batch HDPE was divided into two halves in which the first half of the HDPE was gradually fed to the mini compounder from the feeder, then $\mathrm{OC}$ was fed to the machine using the required filler amount (either $1 \mathrm{wt} . \%$ or $2 \mathrm{wt} . \%)$ and finally the other half of HDPE was added to the composite. The amount of OC in grams were equal to filler weight percent multiplied by the total composition which was fixed to 4 grams. After preparing the batches in the mini compounder, composites were directly extruded into the heated cylinder of the Thermo Scientific ${ }^{\mathrm{TM}} \mathrm{HAAKE}^{\mathrm{TM}}$ MiniJet Pro for injection molding of test specimens (20 $\mathrm{mm}$ diameter and $1.5 \mathrm{~mm}$ thickness) to perform rheological tests. The temperature of the cylinder and the 
mold were $170{ }^{\circ} \mathrm{C}$ and $100{ }^{\circ} \mathrm{C}$, respectively. Finally, molten HDPE-OC was injected with 740 bar for 10 seconds for the mold to take its shape.

\subsection{Characterization of HDPE and HDPE-OC Composites}

Morphological characterizations were carried out on the polymers, additives, and prepared polymer composites to predict and support specific unique properties of the polymer composites. For determining the interlayer spacing and structure of the OC, the percent of crystallinity of semi-crystalline HDPE and morphology of HDPE-OC composites were examined, X-Ray diffraction (XRD) type (X'Pert PRO) from PANlytical was used. As per Bragg's law, peaks produced by XRD are related to the distance between the polymer chains in crystal regions and/or the distance between the OC layers. The X-ray wavelength was

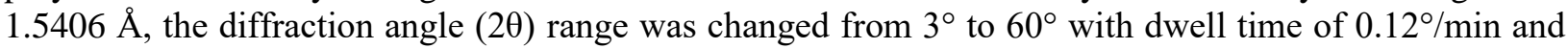
step size of $0.02 \% \mathrm{~min}$. Scanning electron microscopy (SEM) of model Quanta 200 from FEI was used to examine the degree of organoclays' dispersion in HDPE. Samples were coated with a thin layer of gold to enhance the conductivity, increasing the signal, and surface resolution. An accelerating voltage of $30 \mathrm{KV}$ with a magnification of $12000 x$ was used for examined samples.

Thermal analysis is carried out to determine the effect of OCs and their distribution on HDPE thermal transitions. Differential scanning calorimetry (DSC) (Discovery TA instrument) was performed to evaluate the crystallinity and transition temperatures such as melting temperature $\left(\mathrm{T}_{\mathrm{m}}\right)$ and crystallinity temperature $\left(T_{c}\right)$ as well as the degree of crystallinity $\left(X_{c}\right)$ which is calculated using Equation (1) [23],

$X_{c}=\frac{1}{1-m} \frac{\Delta H_{m}}{\Delta H_{m}^{\circ}}$

where $X_{\mathrm{c}}$ represents the degree of crystallinity of the polymer matrix, $m$ represents the filler weight percent (wt. \%), $\Delta \mathrm{H}_{\mathrm{m}}$ is the melting enthalpy of the polymer (measured), and $\Delta \mathrm{H}^{\circ}$ m is the melting enthalpy of $100 \%$ crystalline polymer, which is equal to $2.86 \times 10^{8} \mathrm{~J} / \mathrm{m}^{3}$ for HDPE [24]. Samples were exposed to a heating $\left(25^{\circ} \mathrm{C}-200{ }^{\circ} \mathrm{C}\right)$ and cooling $\left(200{ }^{\circ} \mathrm{C}-25^{\circ} \mathrm{C}\right)$ sequences in a nitrogen atmosphere, at a rate of $20^{\circ} \mathrm{C} / \mathrm{min}$ in DSC. The test was repeated, and the second reading was recorded to erase materials' thermal history. Thermogravimetric analyzer (TGA) from Discovery TA instrument was employed to study the HDPE-OC samples' thermal stability. Like DSC heating process, the sample temperature was elevated from $55^{\circ} \mathrm{C}$ to $650{ }^{\circ} \mathrm{C}$ at a rate of $20{ }^{\circ} \mathrm{C} / \mathrm{min}$ in a nitrogen atmosphere in TGA. The weight loss of the sample is continuously calculated as a function of temperature [25]. Samples for DSC and TGA were prepared by cutting the compounded composites into pieces, approximately mass of 5-7 mg.

Rheological characterization of the samples was used for determining the processability of the polymer composite. Storage modulus $\left(\mathrm{G}^{\prime}\right)$ and complex viscosity $\left(\eta^{*}\right)$ of HDPE-OC composites were measured using parallel plate rheometer (AR2000, TA Instruments). A strain sweep was conducted first to determine the viscoelastic region of all the samples prepared by using an injection molding machine [26]. Frequency of $\omega=1 \mathrm{rad} / \mathrm{s}$ and strain value from $0.1 \%$ to $100 \%$ was used for the strain sweep. Secondly, a frequency sweep in the range 0.1 to $500 \mathrm{rad} / \mathrm{s}$ at a strain magnitude of 0.02 was used. The temperature was maintained at $180^{\circ} \mathrm{C}$ in both strain and frequency sweep.

\subsection{Design of Experiments}

Design of experiment (DOE) is a systemic methodology used to evaluate the effect of multiple factors on one or more responses. The conventional one factor at a time and trial and error experiments requires many runs. On the other hand, DOE is a structured statistical technique that increases experiments' productivity by minimizing the number of experiments involving multiple parameters and maximizing the accuracy of results [27,28]. Many articles have used DOE to analyze the factors affecting specific properties [16,2931]. A well-known type of DOE is the Response Surface Methodology (RSM), a collection of mathematical and statistical techniques useful for the modeling and analyzing problems in which several variables influence the response of interest. The objective is to optimize the process. When searching for the optimum 
results, a model that incorporates curvature is usually required to approximate the response. The second order model is adequate in most cases, as given in Equation (2) [28],

$y=\beta_{0}+\sum_{i=1}^{k} \beta_{i} x_{i}+\sum_{i=1}^{k} \beta_{i i} x_{i}^{2}+\sum \sum \beta_{i j} x_{i} x_{j}$

where, $\mathrm{y}$ represents the response, $x_{i}$ and $x_{j}$ refer to the coded independent variables. $\beta_{0}, \beta_{i}, \beta_{i i}$, and $\beta_{i j}$ are representing the mean value of the response, linear, quadratic, and interaction constant coefficients, respectively. For fitting a second-order mode several methods were proposed, such as Central Composite Design (CCD) and Box-Behnken Designs (BBD). BBD is a design for the RSM. Although the 3k designs deliver a full quadratic model, they are not often used because other designs are much more efficient. One such family of designs is BBD. These designs are essentially fractions of the $3 \mathrm{k}$ designs with additional center points to preserve the design's balance. The original BBD paper describes designs for up to twelve variables [28].

RSM was used to study the effect of the preparation parameter, and the filler amount on the HDPE-OC's thermal and rheological properties. BBD design with three factors; filler content, mixing temperature, and screw speed at three levels; low, L (-), medium, M (0), and high, H (+), was employed. MINITAB software was utilized to do the design of experiments and analyze the results obtained [27]. The range of each factor was selected based on the literature review. Table 1 shows the factors and levels designed by BBD using MINITAB for HDPE-OC composite. Filler amount, mixing temperature and screw speed were used as experimental conditions. A unique code was assigned to each sample. For example, (OC-2-180-120) referees to HDPE mixed with $2 \mathrm{wt} . \%$ of OC prepared at mixing temperature of $180{ }^{\circ} \mathrm{C}$ and a screw speed of $120 \mathrm{rpm}$. The responses in these experiments are $\mathrm{T}_{\mathrm{m}}, \mathrm{T}_{\mathrm{c}}, \mathrm{X}_{\mathrm{c}}, \mathrm{T}_{0.9}, \mathrm{G}^{\prime}$ and $\eta^{*}$ of HDPE-OC composites.

Table 1. Three factors and levels of BBD for HDPE-OC composites

\begin{tabular}{|c|c|c|c|c|c|c|c|c|c|c|}
\hline \multirow[t]{2}{*}{ Run \# } & \multirow[t]{2}{*}{ Sample Codes } & \multicolumn{3}{|c|}{$\begin{array}{l}\text { Filler amount } \\
\text { OC (wt.\%) }\end{array}$} & \multicolumn{3}{|c|}{$\begin{array}{l}\text { Mixing temperature } \\
\left({ }^{\circ} \mathrm{C}\right)\end{array}$} & \multicolumn{3}{|c|}{$\begin{array}{l}\text { Screw speed } \\
(\mathrm{rpm})\end{array}$} \\
\hline & & $\mathrm{L}(-)$ & $M(0)$ & $\mathrm{H}(+)$ & L (-) & $\mathrm{M}(0)$ & $\mathrm{H}(+)$ & $\mathrm{L}(-)$ & $M(0)$ & $\mathrm{H}(+)$ \\
\hline 1 & HDPE-0-165-95 & 0 & & & 165 & & & & 95 & \\
\hline 2 & HDPE-0-180-70 & 0 & & & & 180 & & 70 & & \\
\hline 3 & HDPE-0-180-120 & 0 & & & & 180 & & & & 120 \\
\hline 4 & HDPE-0-195-95 & 0 & & & & & 195 & & 95 & \\
\hline 5 & OC-1-165-70 & & 1 & & 165 & & & 70 & & \\
\hline 6 & OC-1-165-120 & & 1 & & 165 & & & & & 120 \\
\hline 7 & OC-1-180-95 & & 1 & & & 180 & & & 95 & \\
\hline 8 & OC-1-180-95 & & 1 & & & 180 & & & 95 & \\
\hline 9 & OC-1-180-95 & & 1 & & & 180 & & & 95 & \\
\hline 10 & OC-1-195-70 & & 1 & & & & 195 & 70 & & \\
\hline 11 & OC-1-195-120 & & 1 & & & & 195 & & & 120 \\
\hline 12 & OC-2-165-95 & & & 2 & 165 & & & & 95 & \\
\hline 13 & OC-2-180-70 & & & 2 & & 180 & & 70 & & \\
\hline 14 & OC-2-180-120 & & & 2 & & 180 & & & & 120 \\
\hline 15 & OC-2-195-95 & & & 2 & & & 195 & & 95 & \\
\hline
\end{tabular}

\section{RESULTS AND DISCUSSION}

\subsection{Morphology}

XRD results of selected samples of HDPE-OC composites are given in Figure 1. The OC and HDPE-OC composites are generally showing the crystalline peaks in the range between 0 to $10^{\circ}$ of $2 \theta$ [7]. Using Braggs law, the corresponding d-spacing is calculated as $19.40 \AA$ for OC peak at $2 \theta=4.5^{\circ}$. The pure HDPE 
does not show any peaks at the range of examining. The HDPE-OC composite with 2 wt.\% of OC has a peak at around $2 \theta$ equals to $6.8^{\circ}$, equal to $12.98 \AA \mathrm{d}$-spacing. The original peak of $\mathrm{OC}$ is shifted to the right when 2 wt.\% of OC was mixed with HDPE which indicates a decrease in d-spacing [7]. On the other hand, no peak was observed for HDPE-OC composite with $1 \mathrm{wt} . \%$ of OC, which indicates that good dispersion of OC in HDPE is achieved.

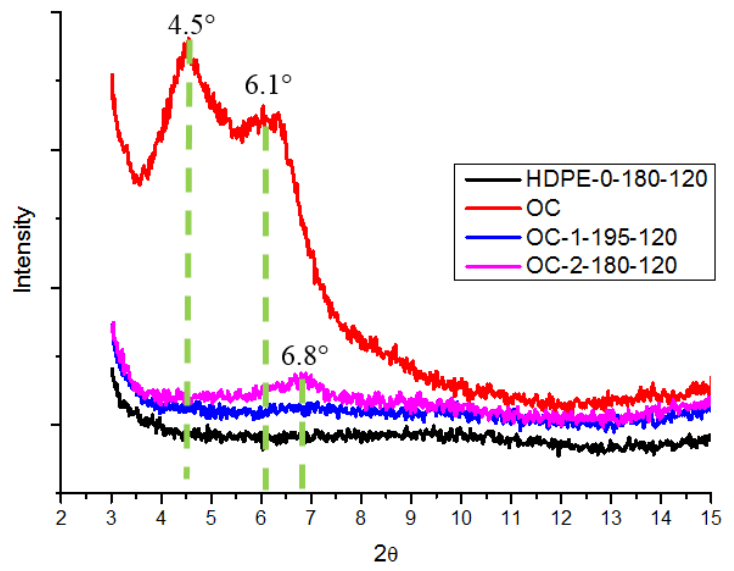

Figure 1. XRD peaks for pure HDPE, Pure OC, and HDPE-OC composite

The SEM image of HDPE-OC composites is shown in Figure 2. Polymer chains penetrate between the clay layers and expand the clay particles in Figure 2 (a). Therefore, many clay layers can be seen clearly. In Figure 2 (b), clay interlayer-polymer interaction seems much lower. Relatively, better dispersion of OC is achieved with the incorporation of $1 \mathrm{wt} . \%$ of OC. Such results could be because of the agglomeration of the clay particles when high loading of OC is used. In other words, polymer chains may not penetrate between the clay layers. Instead, they surround the clay particles by steric interaction, which increases the possibility of clay-clay interaction than clay-polymer interaction.
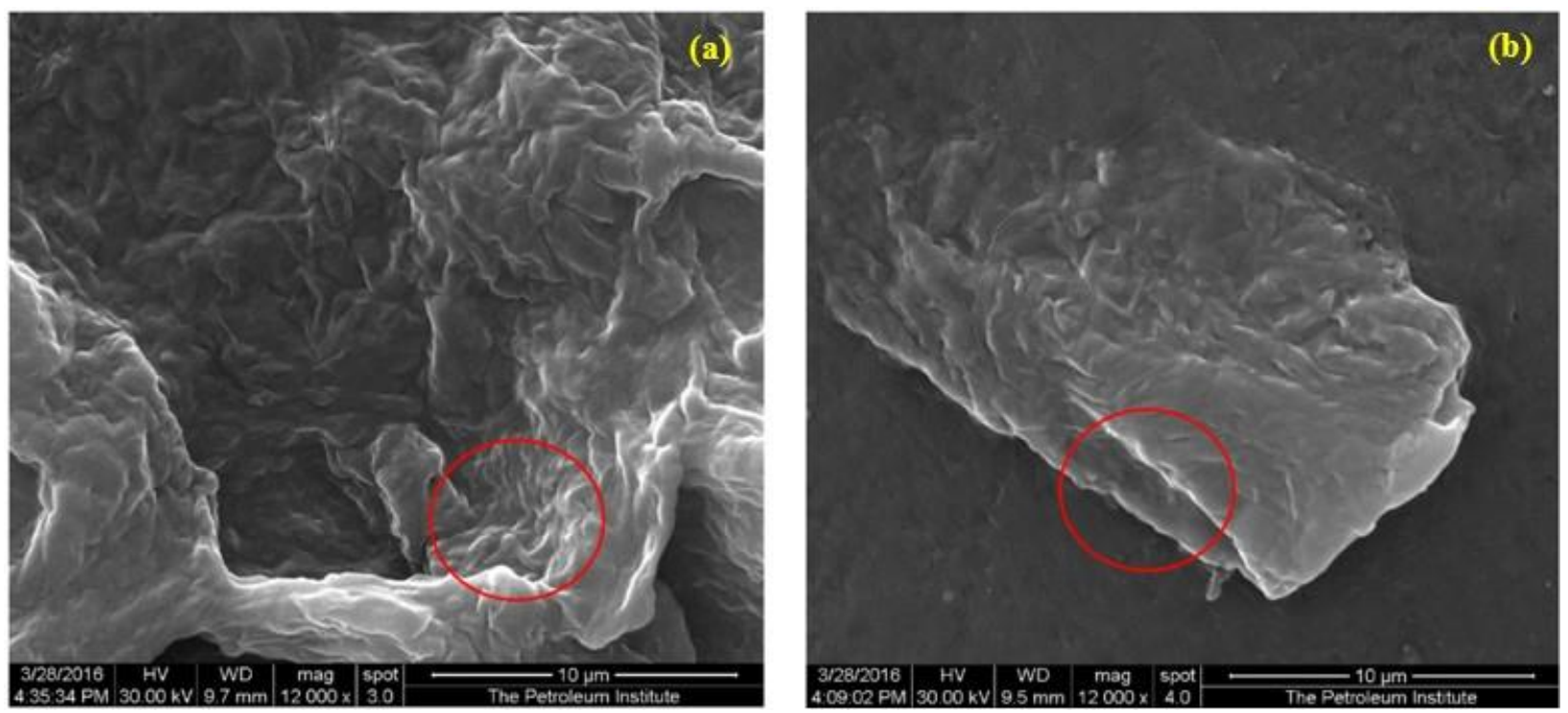

Figure 2. SEM of HDPE-OC composites; a) OC-1-165-70, and b) OC-2-180-70

\subsection{Thermal Analysis}

Thermal properties and thermal stability of HDPE-OC composite were determined by DSC and TGA, as summarized in Table 2. In general, $\mathrm{T}_{\mathrm{m}}, \mathrm{T}_{\mathrm{c}}$ and $\mathrm{X}_{\mathrm{c}}$ of the samples varied between $132.12-136.56{ }^{\circ} \mathrm{C}, 113.10$ $117.49^{\circ} \mathrm{C}$, and $62.58-70.30 \%$, respectively. The crystallinity of HDPE was reduced by the addition of 1 wt\%. OC which implies the better interaction between the polymer and organoclay interlayers than polymer-polymer or polymer-organoclay interactions. The maximum improvement on the thermal stability 
of HDPE were achieved by 1 wt. \% OC addition to HDPE at $180{ }^{\circ} \mathrm{C}$ with $95 \mathrm{rpm}$ screw speed. Higher filler content should cause a higher thermal stability, however $1 \mathrm{wt} . \%$ OC dispersed better than $2 \mathrm{wt} . \%$ OC in HDPE as it is supported by morphological results given in section 3.1, therefore it improved the thermal stability with higher interaction between the organoclay interlayer and HDPE. Changing the screw speed from $70 \mathrm{rpm}$ to $120 \mathrm{rpm}$ while fixing the other parameters, caused a decrease in the thermal stability. The use of the mixing temperature of $165^{\circ} \mathrm{C}$ leads to slightly better thermal stability than $195^{\circ} \mathrm{C}$.

\subsection{Rheological Analysis}

Rheological properties of composites such as storage modulus $\mathrm{G}^{\prime}$ and complex viscosity $\eta^{*}$ at an angular frequency of $\omega=0.1 \mathrm{rad} / \mathrm{s}$ are determined as given in Table 2 .

Table 2. Thermal and rheological properties of HDPE-OC composites

\begin{tabular}{|l|l|l|l|l|l|l|}
\hline Samples & $\mathrm{T}_{\mathrm{m}}\left({ }^{\circ} \mathrm{C}\right)$ & $\mathrm{T}_{\mathrm{c}}\left({ }^{\circ} \mathrm{C}\right)$ & $\mathrm{X}_{\mathrm{c}}(\%)$ & $\mathrm{T}_{0.9}\left({ }^{\circ} \mathrm{C}\right)$ & $\mathrm{G}(\mathrm{Pa})$ & $\eta^{*}(\mathrm{~Pa} . \mathrm{s})$ \\
\hline HDPE-0-165-95 & 133.21 & 116.39 & 70.23 & 407.24 & 269.87 & 9237.65 \\
\hline HDPE-0-180-70 & 132.27 & 117.46 & 69.75 & 430.89 & 350.69 & 11228.30 \\
\hline HDPE-0-180-120 & 133.24 & 116.04 & 70.30 & 442.98 & 267.55 & 8490.10 \\
\hline HDPE-0-195-95 & 133.60 & 116.45 & 69.30 & 388.38 & 391.23 & 12032.40 \\
\hline OC-1-165-70 & 133.29 & 116.73 & 67.41 & 435.25 & 741.47 & 17717.20 \\
\hline OC-1-165-120 & 134.98 & 114.94 & 66.77 & 441.82 & 1004.48 & 23495.30 \\
\hline OC-1-180-95 & 136.27 & 113.55 & 67.43 & 440.44 & 428.94 & 10556.10 \\
\hline OC-1-180-95 & 135.50 & 113.99 & 62.58 & 436.18 & 429.00 & 10555.70 \\
\hline OC-1-180-95 & 136.56 & 113.10 & 64.08 & 447.40 & 428.90 & 10556.00 \\
\hline OC-1-195-70 & 133.17 & 116.23 & 68.08 & 431.38 & 362.95 & 8099.68 \\
\hline OC-1-195-120 & 133.60 & 114.77 & 66.75 & 433.71 & 352.56 & 10215.30 \\
\hline OC-2-165-95 & 133.25 & 116.06 & 67.50 & 428.89 & 831.47 & 21126.30 \\
\hline OC-2-180-70 & 133.47 & 116.26 & 66.26 & 426.23 & 776.59 & 16137.40 \\
\hline OC-2-180-120 & 132.12 & 117.49 & 65.35 & 401.16 & 349.96 & 10066.90 \\
\hline OC-2-195-95 & 134.51 & 114.92 & 67.22 & 423.25 & 298.57 & 6593.12 \\
\hline
\end{tabular}

When the values of storage modulus and complex viscosity of HDPE-0-165-95 and OC-2-165-95 are compared, we can see that adding $2 \mathrm{wt} . \%$ of OC increases storage modulus and complex viscosity of HDPE by $308 \%$ and $229 \%$, respectively. In general, increased temperature causes a decrease in the storage modulus and complex viscosity of polymers at constant angular frequency. The polymer chains can be more aligned and the molten polymer chains can easily flow on each other as temperature increases. Also, addition of organoclays to polymer causes and obstacles to flow, and higher chance to interact polymer chains interacted with organophilic clay layers, eventually both the storage modulus and complex viscosity increases.

Log-log curves of $\mathrm{G}^{\prime}$ and $\eta^{*}$ of selected HDPE-OC composites were plotted as a function of $\omega$ in Figure 3 (a) and (b), respectively. 

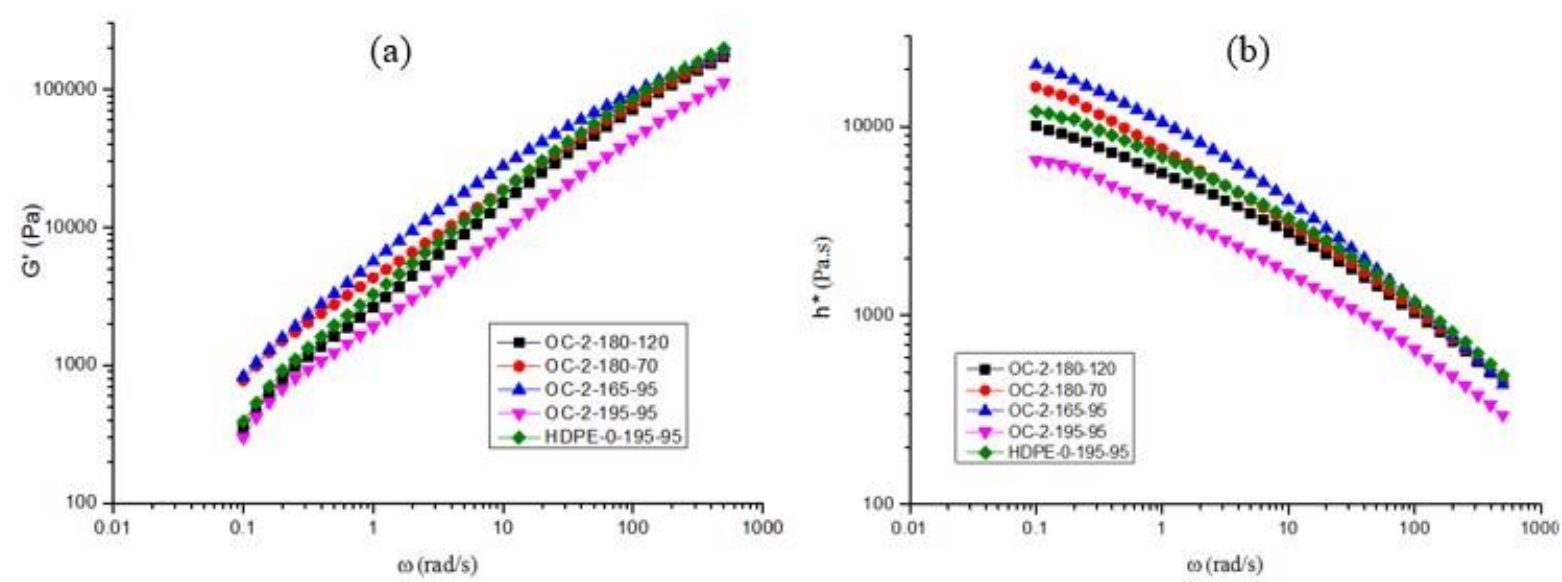

Figure 3. Based on the angular velocity of HDPE-OC composites; a) storage modulus, and b) complex viscosity

Adding 2 wt. $\%$ of OC to HDPE marginally decreased G', and dramatically decreased $\eta^{*}$. HDPE-OC composites prepared using $120 \mathrm{rpm}$ as screw speed (OC-2-180-120) have a lower value of $\mathrm{G}^{\prime}$ and $\eta^{*}$ than values obtained when $70 \mathrm{rpm}$ is used (OC-2-180-70). Higher $\mathrm{G}^{\prime}$ and $\eta^{*}$ values were obtained when mixing temperature of $165{ }^{\circ} \mathrm{C}$ is used (OC-2-165-95). These values were significantly reduced when mixing temperature is elevated to $195{ }^{\circ} \mathrm{C}$ (OC-2-195-95). The observed increment of $\mathrm{G}^{\prime}$ means that the elastic behavior of HDPE-OC composites is enhanced.

\subsection{Statistical Analysis}

Analysis of variance (ANOVA) is utilized to evaluate the significance of investigated factors on the responses such as $\mathrm{T}_{\mathrm{m}}, \mathrm{T}_{\mathrm{c}}, X_{c}, \mathrm{~T}_{0.9}, \mathrm{G}^{\prime}$ and $\eta^{*}$ as shown in Table 3 . Factors investigated includes OC amount (wt.\%), mixing temperature and screw speed. For all the ANOVA test carried in this section a 95\% confidence was used. In other words, the factors or models tested are considered significant if they have a probability (P-value) less than 0.05 . The correlation coefficient $\left(\mathrm{R}^{2}\right)$ is defined as the ratio of the explained variation to the total variation. When $\mathrm{R}^{2}$ approaches unity, a better fit of the response model is achieved and consequently the prediction of the actual values will be better. Finally, the relationship between the responses and factors were fitted into a second-order quadratic equation. The general equation is given in Equation (3),

$y=\underbrace{\beta_{0}}_{\text {Constant }}+\underbrace{\beta_{1} x_{1}+\beta_{2} x_{2}+\beta_{3} x_{3}}_{\text {Linear }}+\underbrace{\beta_{11} x_{1}^{2}+\beta_{22} x_{2}^{2}+\beta_{33} x_{3}^{2}}_{\text {Square }}+\underbrace{\beta_{12} x_{1} x_{2}+\beta_{13} x_{1} x_{3}+\beta_{23} x_{2} x_{3}}_{\text {Interaction }}$

where $\beta_{0}$ is the constant, $\beta_{1}, \beta_{2}$ and $\beta_{3}$ referees to the coefficients of $x_{1}=$ wt. $\%$ of OC, $x_{2}=$ mixing temperature and $x_{3}=$ screw speed, respectively.

Table 3. Analysis of Variance (ANOVA) for $T_{m}$, $T_{c}$ and $X_{c}$ of HDPE-OC Composites

\begin{tabular}{|l|l|l|l|l|l|l|l|l|}
\hline Responses & \multicolumn{2}{l|}{$\mathrm{T}_{\mathrm{m}}$} & \multicolumn{2}{l}{$\mathrm{T}_{\mathrm{c}}$} & $\mathrm{X}_{\mathrm{c}}$ & \multicolumn{2}{l|}{$\mathrm{T}_{0.9}$} \\
\hline Source & F-test & P-value & F-test & P-value & F-test & P-value & F-test & P-value \\
\hline Linear & 0.31 & 0.815 & 1.69 & 0.283 & 2.56 & 0.168 & 0.21 & 0.889 \\
\hline Square & 12.23 & 0.010 & 14.71 & 0.006 & 3.19 & 0.122 & 2.06 & 0.224 \\
\hline Interaction & 1.18 & 0.406 & 1.66 & 0.289 & 0.09 & 0.965 & 0.45 & 0.731 \\
\hline
\end{tabular}

Among the three primary sources of the linear, square and interaction, only the square term is considered significant for $\mathrm{T}_{\mathrm{m}}$ and $\mathrm{T}_{\mathrm{c}}$. On the other hand, the ANOVA of $\mathrm{X}_{\mathrm{c}}$ and $\mathrm{T}_{0.9}$ is showing that none of the sources is significant. Figure 4 shows a response surface plot of $T_{m}, T_{c}$ and $X_{c}$, respectively. Loading a low amount of OC causes a decrease in $\mathrm{T}_{\mathrm{m}}$. However, loading a high amount of OC causes an increase in $\mathrm{T}_{\mathrm{c}}$. Similarly, using a high or low value of screw speed in mixing leads to a decrease in $T_{m}$ or increase in $T_{c}$, respectively. 
Using high wt. \% of OC causes a drop in $\mathrm{X}_{\mathrm{c}}$ due to dispersing the organoclay in HDPE and avoiding the form of crystal regions. Furthermore, small curvature is detected in the curve which refers to the OC square term (P-value $=0.052)$. In most cases, the incorporation of filler into the polymer matrix has a significant effect on the composite's thermal stability [26]. It is observed that the amount of OC is affecting the most the $\mathrm{T}_{0.9}$ yet it is considered an insignificant factor $(\mathrm{P}$-value $=0.077)$. Mixing temperature and screw speed do not affect $\mathrm{T}_{0.9}$.
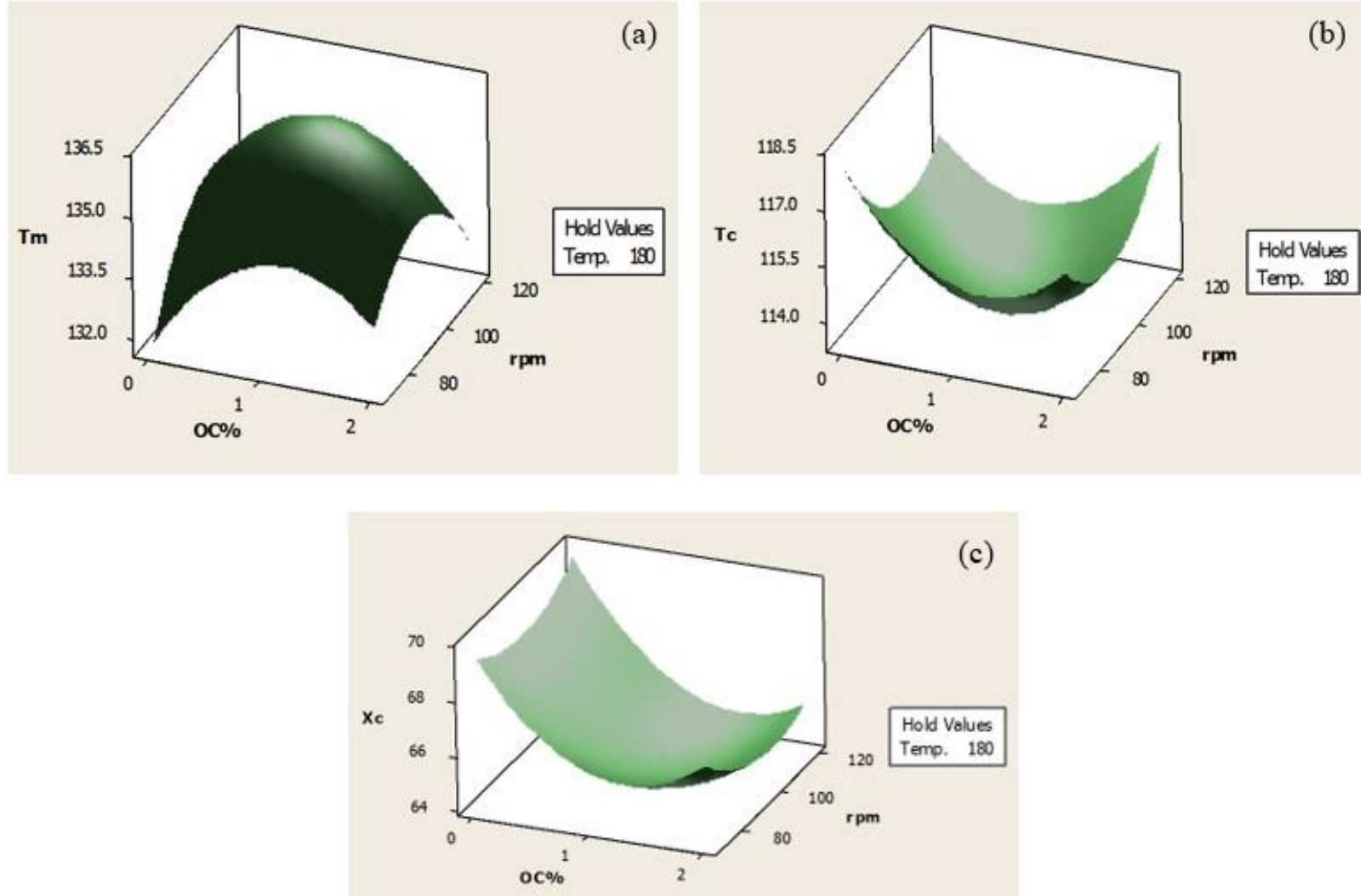

Figure 4. Response surface plots for a) melting temperature $\left(T_{m}\right)$, b) crystallization temperature $\left(T_{c}\right)$, and c) crystallinity $\left(X_{c}\right)$ of HDPE-OC composites

Table 4 shows the analysis of variance of $\mathrm{G}^{\prime}$ and $\eta^{*}$ of HDPE-OC composites. For $\mathrm{G}^{\prime}$, it is concluded that none of the sources is considered significant as the values of P-values are more than 0.05. The ANOVA of $\eta *$ shows that the linear terms are significant in overall.

Table 4. Analysis of Variance (ANOVA) for storage modulus ( $\left.G^{\prime}\right)$ and complex viscosity ( $\left.\eta^{*}\right)$ of HDPEOC composites

\begin{tabular}{|c|c|c|c|c|}
\hline Responses & \multicolumn{2}{|l|}{$G^{\prime}$} & \multicolumn{2}{|l|}{$\eta^{*}$} \\
\hline Source & F-test & P-value & F-test & P-value \\
\hline Linear & 5.35 & 0.051 & 5.65 & 0.046 \\
\hline Square & 1.28 & 0.377 & 1.27 & 0.380 \\
\hline Interaction & 2.14 & 0.213 & 2.68 & 0.158 \\
\hline
\end{tabular}

Figure 5 illustrates the effect of mixing temperature and $\mathrm{OC}$ amount (wt.\%) on the storage modulus and complex viscosity of the HDPE-OC composites. 

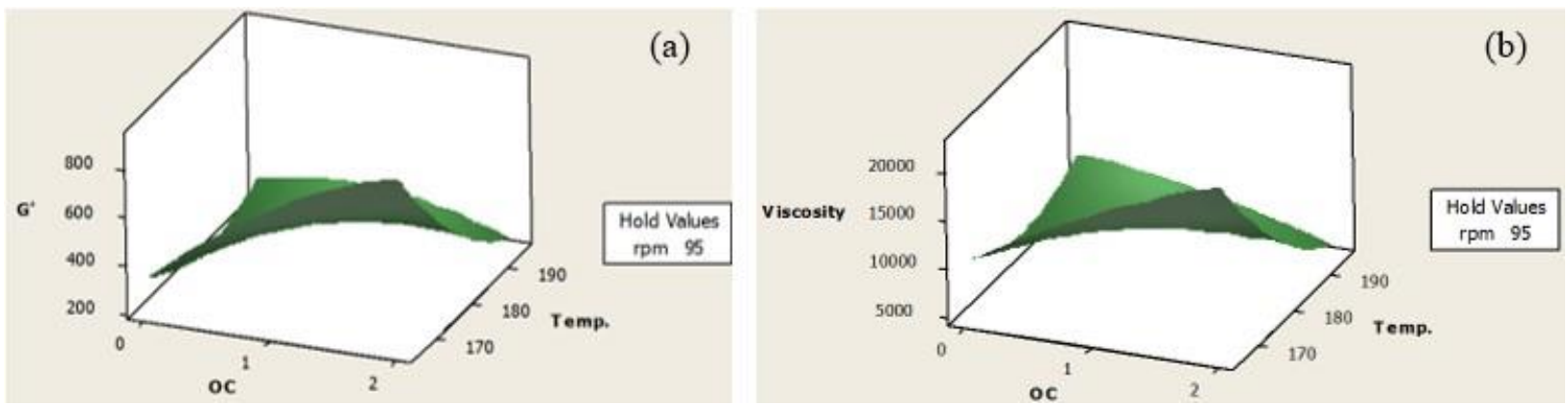

Figure 5. Response surface plots of HDPE-OC composites for a) storage modulus $\left.\left(G^{\prime}\right), b\right)$ complex viscosity $\left(\eta^{*}\right)$

In Figure 5 (a) and (b), both storage modulus and complex viscosity increase at low mixing temperature and high organoclay amount due to organoclay particles strength the bonds as a bridge between the polymer chains which require higher energy for elastic deformation and increases the resistance to flow [32-34]. The mixing temperature and the interaction effect between the mixing temperature and $\mathrm{OC}$ wt. $\%$ are considered significant factors affecting the $\eta^{*}$ of the HDPE-OC composites as it given in Figure 5 (b).

All the fitted equations of the analyzed responses along with their corresponding $\mathrm{R}^{2}$ are listed in Table 5 . Equations are valid over the investigated range of the selected factors given in Table 1.

Table 5. Coefficients of fitted equations for HDPE-OC composites

\begin{tabular}{|c|c|}
\hline General Fitted Equations for the Responses (Equation 3) & $\mathrm{R}^{2}$ \\
\hline $\begin{array}{l}\mathrm{T}_{\mathrm{m}}=-10.6979+3.1653 \mathrm{x}_{1}+1.2521 \mathrm{x}_{2}+0.6727 \mathrm{x}_{3}-1.7241 \mathrm{x}_{1}^{2}-0.0033 \mathrm{x}_{2}^{2}-0.0026 \mathrm{x}_{3}^{2}+0.0145 \mathrm{x}_{1} \mathrm{X}_{2}-0.0231 \\
\mathrm{x}_{1} \mathrm{x}_{3}-0.0008 \mathrm{x}_{2} \mathrm{x}_{3}\end{array}$ & $89.17 \%$ \\
\hline $\begin{array}{l}\mathrm{T}_{\mathrm{c}}=234.964-2.6501 \mathrm{x}_{1}-1.0267 \mathrm{x}_{2}-0.5358 \mathrm{x}_{3}+1.7762 \mathrm{x}_{1}^{2}+0.0028 \mathrm{x}_{2}^{2}+0.0024 \mathrm{x}_{3}^{2}-0.0201 \mathrm{x}_{1} \mathrm{x}_{2}+0.0265 \\
\mathrm{x}_{1} \mathrm{x}_{3}+0.0002 \mathrm{x}_{2} \mathrm{x}_{3}\end{array}$ & $91.55 \%$ \\
\hline $\begin{array}{l}\mathrm{X}_{\mathrm{c}}=307.904-6.771 \mathrm{x}_{1}-2.5362 \mathrm{x}_{2}-0.2057 \mathrm{x}_{3}+2.2653 \mathrm{x}_{1}^{2}+0.0071 \mathrm{x}_{2}^{2}+0.0015 \mathrm{x}_{3}^{2}+0.011 \mathrm{x}_{1} \mathrm{x}_{2}-0.0146 \mathrm{x}_{1} \mathrm{x}_{3} \\
-0.0005 \mathrm{x}_{2} \mathrm{x}_{3}\end{array}$ & $77.78 \%$ \\
\hline $\begin{array}{l}\mathrm{T}_{0.9}=-892.895+36.5121 \mathrm{x}_{1}+15.0832 \mathrm{x}_{2}-0.2906 \mathrm{x}_{3}-19.8123 \mathrm{x}_{1}^{2}-0.0426 \mathrm{x}_{2}^{2}+0.0061 \mathrm{x}^{2}+0.2204 \mathrm{x}_{1} \mathrm{x}_{2}- \\
0.3716 \mathrm{x}_{1} \mathrm{x}_{3}-0.0028 \mathrm{x}_{2} \mathrm{x}_{3}\end{array}$ & $91.55 \%$ \\
\hline $\begin{array}{l}\mathrm{G}^{\prime}=12624.5+2571.59 \mathrm{x}_{1}-142.2 \mathrm{x}_{2}+8.3831 \mathrm{x}_{3}-80.1652 \mathrm{x}_{1}{ }^{2+} 0.44 \mathrm{x}_{2}{ }^{2}+0.1399 \mathrm{x}_{3}{ }^{2}-10.9044 \mathrm{x}_{1} \mathrm{x}_{2}-3.4349 \mathrm{x}_{1} \mathrm{x}_{3} \\
-0.182 \mathrm{x}_{2} \mathrm{x}_{3}\end{array}$ & $84.03 \%$ \\
\hline $\begin{array}{l}\prod^{*}=355938+58476.1 \mathrm{x}_{1}-3841.98 \mathrm{x}_{2}-72.7594 \mathrm{x}_{3}-854.88 \mathrm{x}_{1}^{2}+11.317 \mathrm{x}_{2}^{2}+2.8474 \mathrm{x}_{3}^{2}-288.799 \mathrm{x}_{1} \mathrm{x}_{2}- \\
33.323 \mathrm{x}_{1 \times 3}-2.44 \mathrm{x}_{2} \mathrm{x}_{3}\end{array}$ & $85.21 \%$ \\
\hline
\end{tabular}

$\mathrm{x}_{1}=\mathrm{OC}$ wt. $\%, \mathrm{x}_{2}=$ mixing temperature, and $\mathrm{x}_{3}=$ screw speed.

Confirmation experiments were performed for the responses to verify the adequacy of obtained mathematical models. Samples of confirmation were selected to be in the range of the used factors in obtaining the models. HDPE composite with $0.3 \mathrm{wt} . \% \mathrm{OC}$ was prepared at mixing temperature of $170 \mathrm{C}^{\circ}$ and screw speed of $80 \mathrm{rpm}$ is used for the verification test. The result of the confirmation runs and their comparisons with the predicted values for various responses are listed in Table 6. Most of the percentage errors are in the acceptable range (less than $5 \%$ ) except rheological parameters.

Table 6. Results of verification experiments

\begin{tabular}{|l|l|l|l|l|}
\hline Sample & Response & Predicted & \multicolumn{1}{|c|}{ Actual } & \% Change \\
\hline \multirow{5}{*}{ OC-0.3-170-80 } & $\mathrm{T}_{\mathrm{m}}\left({ }^{\circ} \mathrm{C}\right)$ & 133.86 & 134.66 & 0.59 \\
\cline { 2 - 5 } & $\mathrm{T}_{\mathrm{c}}\left({ }^{\circ} \mathrm{C}\right)$ & 115.95 & 114.33 & 1.39 \\
\cline { 2 - 5 } & $\mathrm{X}_{\mathrm{c}}(\%)$ & 68.10 & 68.80 & 1.03 \\
\cline { 2 - 5 } & $\mathrm{T}_{0.9}\left({ }^{\circ} \mathrm{C}\right)$ & 428.41 & 431.30 & 0.67 \\
\cline { 2 - 5 } & $\mathrm{G}^{\prime}(\mathrm{Pa})$ & 379.41 & 242.99 & 35.95 \\
\cline { 2 - 5 } & $\mathrm{h}^{*}(\mathrm{~Pa} . \mathrm{s})$ & 10996.25 & 7067.09 & 35.73 \\
\hline
\end{tabular}


The final stage is to find the best combination of the mixing factor to achieve the best results. Multi-response optimization means determining the values of controllable factors that give the best possible value of all the responses in combination. Selected responses to optimize are $\mathrm{T}_{\mathrm{m}}, \mathrm{T}_{0.9}, \mathrm{G}^{\prime}, \eta^{*}$. In multi-response optimization, desired weight is given to each response. The higher the importance of the response, the higher the weightage; however, equal weight is used in the present study. Regarding the combined influences of all the responses desirability is determined by varying values of input parameters. Table 7 shows the range of responses and their desired goals, along with the importance weights assigned to each response.

Table 7. Range of responses and their desired goals

\begin{tabular}{|l|l|l|l|l|}
\hline Composite & Response & Goal & Lower limit & Upper limit \\
\hline \multirow{4}{*}{ HDPE-OC } & $\mathrm{T}_{\mathrm{m}}\left({ }^{\circ} \mathrm{C}\right)$ & Maximize & 133 & -- \\
\cline { 2 - 5 } & $\mathrm{T}_{0.9}\left({ }^{\circ} \mathrm{C}\right)$ & Maximize & 400 & -- \\
\cline { 2 - 5 } & $\mathrm{G}^{\prime}(\mathrm{Pa})$ & Maximize & 400 & -- \\
\cline { 2 - 5 } & $\eta^{*}(\mathrm{~Pa} . \mathrm{s})$ & Minimize & -- & 15000 \\
\hline
\end{tabular}

Response optimizer of MINITAB software was used to find the optimal values. Figure 6 shows the optimum values and the corresponding optimum factors for HDPE-OC composites. The optimum parameters for HDPE-OC composite are $1.5 \mathrm{wt} . \%$ of OC as a filler, mixing temperature of $183{ }^{\circ} \mathrm{C}$, and screw speed of $77 \mathrm{rpm}$. And the corresponding obtained responses are $\mathrm{T}_{\mathrm{m}}=135^{\circ} \mathrm{C}, \mathrm{T}_{0.9}=442{ }^{\circ} \mathrm{C}, \mathrm{G}^{\prime}=530.6$ $\mathrm{Pa}$ and $\eta^{*}=11380$ Pa.s.

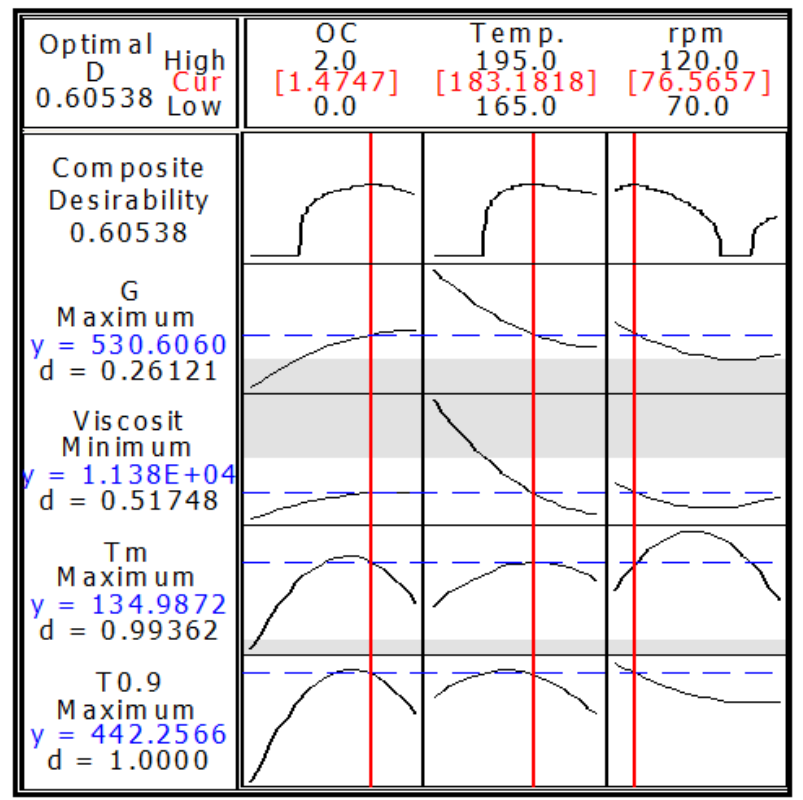

Figure 6. Optimal values of responses and parameters of HDPE-OC

Table 8 shows the actual versus predicted thermal properties of HDPE-OC prepared using optimum processing condition. Good agreement is observed between the actual and predicted values.

Table 8. Actual and predicted values for optimum processing condition

\begin{tabular}{|l|l|l|l|l|}
\hline Sample & Response & Predicted & Actual & \% Change \\
\hline \multirow{4}{*}{ OC-1.5-183-77 } & $\mathrm{T}_{\mathrm{m}}\left({ }^{\circ} \mathrm{C}\right)$ & 135.0 & 136.5 & 1.11 \\
\cline { 2 - 5 } & $\mathrm{T}_{\mathrm{c}}\left({ }^{\circ} \mathrm{C}\right)$ & 114.6 & 113.2 & 1.22 \\
\cline { 2 - 5 } & $\mathrm{X}_{\mathrm{c}}(\%)$ & 65.3 & 62.0 & 5.05 \\
\hline
\end{tabular}




\section{CONCLUSION}

HDPE, thermoplastic semicrystalline polymer, was mixed with different amounts of organoclay (OC) using a melt blending method to prepare the HDPE-OC composites. The effect of organoclay on the morphological, thermal, and rheological behavior of HDPE were tested. SEM and XRD results showed that better dispersion was achieved with the addition of 1 wt. \% of OC in HDPE using $165{ }^{\circ} \mathrm{C}$ as a mixing temperature as compared to the addition of $2 \mathrm{wt} . \%$ of OC in HDPE at $180{ }^{\circ} \mathrm{C}$ mixing temperature, where $70 \mathrm{rpm}$ used as a screw speed for both composites. The effect of organoclay amount as a processing parameter on enhancing the thermal properties, melting temperature, crystallinity temperature and percentage of HDPE crystallinity is found significant. The screw speed has no significant effect on the thermal and rheological properties of HDPE-OC composites; however, the multiplication of screw speed found to have a significant effect on the melting and crystallinity temperature. Mixing temperature is the only linear factor that affecting the storage modulus $\left(\mathrm{G}^{\prime}\right)$ and complex viscosity $\left(\eta^{*}\right)$ significantly. Also, the interaction between mixing temperature and the amount of $\mathrm{OC}$ is significantly affecting the $\eta^{*}$ of HDPE-OC composite.

RSM was used to fit the obtained data to second-order equations. Verification experiments were conducted to verify the availability of obtained models, and the results were in good agreement with values predicted from the experiments. Nevertheless, the storage modulus ( $\left.\mathrm{G}^{\prime}\right)$ and complex viscosity $\left(\eta^{*}\right)$ were not fitted well to second-order equations. Optimum processing parameters were found for the HDPE-OC composite. Such information is also valuable for the researchers working in the polymer application industry such as automotive, packaging, and pipe. The thermal and rheological properties of HDPE composites can be tailored to achieve favorable flow behavior of composite for processing and shaping of the final products industrially such as sturdy bottles, bags, tanks, water pipes, and jugs. Although optimum processing conditions can be found using the constructed model, the further experiments are suggested to be done to achieve a better prediction of composite's rheological properties.

\section{CONFLICTS OF INTEREST}

No conflict of interest was declared by the authors.

\section{ACKNOWLEDGEMENTS}

The authors would like to thank Borouge Innovation Center to provide HDPE, and Khalifa University for completing the experimental work in their research labs. The authors acknowledge the invaluable feedback provided by Prof. Dr. Chris Macosko (Emeritus Professor in Chemical Engineering and Materials Science, University of Minnesota, USA), on the draft of this manuscript.

\section{REFERENCES}

[1] Fu, S., Sun, Z., Huang, P., Li, Y., Hu, N., "Some basic aspects of polymer nanocomposites: A critical review", Nano Materials Science, 1(1): 2-30, (2019).

[2] Bhattacharya, M., "Polymer Nanocomposites-A Comparison between Carbon Nanotubes, Graphene, and Clay as Nanofillers", Materials, 9(4): 262, (2016).

[3] Ray, S.S., Okamoto, M., "Polymer/layered silicate nanocomposites: a review from preparation to processing”, Progress in Polymer Science, 28(11): 1539-1641, (2003).

[4] Li, J., Gunister, E., Barsoum, I., "Effect of graphene oxide as a filler material on the mechanical properties of LLDPE nanocomposites", Journal of Composite Materials, 53(19): 2761-2773, (2019). 
[5] Chafidz, A., Ali, M.A., Elleithy, R., "Morphological, thermal, rheological, and mechanical properties of polypropylene-nanoclay composites prepared from masterbatch in a twin-screw extruder", Journal of Materials Science, 46(18): 6075-6086, (2011).

[6] Ray, S.S., "Clay-Containing Polymer Nanocomposites: From Fundamentals to Real Applications", Elsevier Publishing, United Kingdom, 1-387, (2013).

[7] Gunister, E., Cobanoglu, İ., İsci, S., "The effect of polyurethane on NaMt and OnaMt dispersions," Progress in Organic Coatings, 65(3): 357-361, (2009).

[8] Theng, B.K.G., "Clay-Polymer Interactions: Summary and Perspectives", Clays and Clay Minerals, 30(1): 1-10, (1982).

[9] Katti, D.R., Katti, K.S., Raviprasad, M., Gu, C., "Role of Polymer Interactions with Clays and Modifiers on Nanomechanical Properties and Crystallinity in Polymer Clay Nanocomposites", Journal of Nanomaterials, 15, (2012).

[10] Rahman, Md.R., "Silica and Clay Dispersed Polymer Nanocomposites", In Woodhead Publishing Series in Composites Science and Engineering, Woodhead Publishing, (2018).

[11] Peacock, A.J., Handbook of polyethylene: structures, properties, and applications, New York: Marcel Dekker, (2000).

[12] Gabr, M.H., Okumura, W., Ueda, H., Kuriyama, W., Uzawa, K., Kimpara, I., "Mechanical and thermal properties of carbon fiber/polypropylene composite filled with nano-clay", Composites Part B: Engineering, 69: 94-100, (2015).

[13] Chen, C., Samaniuk, J., Baird, D.G., Devoux, G., Zhang, M., Moore, R.B., Quigley, J.P., “The preparation of nano-clay/polypropylene composite materials with improved properties using supercritical carbon dioxide and a sequential mixing technique", Polymer, 53(6): 1373-1382, (2012).

[14] Arunvisut, S., Phummanee, S., Somwangthanaroj, A., "Effect of clay on mechanical and gas barrier properties of blown film LDPE/clay nanocomposites", Journal of Applied Polymer Science, 106(4): 2210-2217, (2007).

[15] Osman, M.A., Rupp, J.E.P., Suter, U.W., "Effect of non-ionic surfactants on the exfoliation and properties of polyethylene-layered silicate nanocomposites", Polymer, 46(19): 8202-8209, (2005).

[16] Ramachandran, A., George, K.E., George, T.S., Krishnan, A., "Optimisation of processing conditions of PP/HDPE/nano kaolinite clay composites by response surface methodology", International Journal of Plastics Technology, 16(2): 136-149, (2012).

[17] Hwang, S., Liu, S., Hsu, P.P., Yeh, J., Yang, J., Chang, K., Chu, S., "Morphology, mechanical, thermal and rheological behavior of microcellular injection molded TPO-clay nanocomposites prepared by kneader", International Communications in Heat and Mass Transfer, 38(5): 597-606, (2011).

[18] Wang, K.H., Choi, M.H., Koo, C.M., Xu, M., Chung, I.J., Jang, M.C., Choi, S.W.,Song, H.H., "Morphology and physical properties of polyethylene/silicate nanocomposite prepared by melt intercalation", Journal of Polymer Science Part B: Polymer Physics, 40(14): 1454-1463, (2002).

[19] Lee, J.H., Jung, D., Hong, C.E., Rhee, K.Y., Advani, S.G., "Properties of polyethylene-layered silicate nanocomposites prepared by melt intercalation with a PP-g-MA compatibilizer", Composites Science and Technology, 65(13): 1996-2002, (2005). 
[20] Ghanbari, A., Heuzey, M.C., Carreau, P.J., Ton-That, M.T., "Morphological and rheological properties of PET/clay nanocomposites", Rheologica Acta, 52(1): 59-74, (2013).

[21] Grigoriadi, K., Giannakas, A., Ladavos, A., Barkoula, N.M., "Thermomechanical behavior of polymer/layered silicate clay nanocomposites based on unmodified low density polyethylene", Polymer Engineering \& Science, 53(2): 301-308, (2013).

[22] https://sigmachemtrade.com/wp-content/uploads/2019/08/BB2588-.pdf, Access date: 24.01.2022

[23] Jiang, X., Drzal, L.T., "Multifunctional high density polyethylene nanocomposites produced by incorporation of exfoliated graphite nanoplatelets 1: Morphology and mechanical properties", Polymer Composite, 31(6): 1091-1098, (2010).

[24] Crist, B., Mirabella, F.M., "Crystal thickness distributions from melting homopolymers or random copolymers", Journal of Polymer Science Part B: Polymer Physics, 37(21): 3131-3140, (1999).

[25] Gunister, E., Pestreli, D., Unlu, C.H., Atıc1, O., Gungor, N., "Synthesis and characterization of chitosan-MMT biocomposite systems", Carbohydrate Polymers, 67(3): 358-365, (2007).

[26] Durmus, A., Woo, M., Kasgoz, A., Macosko, C.W., Tsapatsis, M., "Intercalated linear low density polyethylene (LLDPE)/clay nanocomposites prepared with oxidized polyethylene as a new type compatibilizer: Structural, mechanical and barrier properties", European Polymer Journal, 43(9): 3737-3749, (2007).

[27] Mathews, P.G., Design of experiments with MINITAB. Milwaukee, Wis: ASQ Quality Press, (2005).

[28] Montgomery, D.C., Design and Analysis of Experiments. John Wiley \& Sons, (2008).

[29] Balachandran, M., Devanathan, S., Muraleekrishnan, R., Bhagawan, S.S., "Optimizing properties of nanoclay-nitrile rubber (NBR) composites using Face Centred Central Composite Design," Materials Design, 35: 854-862, (2012).

[30] Kukreja, T.R., Kumar, D., Prasad, K., Chauhan, R.C., Choe, S., Kundu, P.P., "Optimisation of physical and mechanical properties of rubber compounds by response surface methodology-Two component modelling using vegetable oil and carbon black", European Polymer Journal, 38(7): 1417-1422, (2002).

[31] Chaudhuri, S., Chakraborty, R., Bhattacharya, P., "Optimization of biodegradation of natural fiber (Chorchorus capsularis): HDPE composite using response surface methodology", Iranian Polymer Journal, 22(11): 865-875, (2013).

[32] Acharya, H., Srivastava, S. K., "Influence of nanodispersed organoclay on rheological and swelling properties of ethylene propylene diene terpolymer", Macromolecular Research, 14(2): 132-139, (2006).

[33] Dong, Y., Bhattacharyya, D., "Effects of clay type, clay/compatibilizer content and matrix viscosity on the mechanical properties of polypropylene/organoclay nanocomposites", Composites Part A: Applied Science and Manufacturing, 39(7): 1177-1191, (2008).

[34] Zhang, G., Wu, T., Lin, W., Tan, Y., Chen, R., Huang, Z., Yin, X., Qu, J., "Preparation of polymer/clay nanocomposites via melt intercalation under continuous elongation flow", Composites Science and Technology, 145: 157-164, (2017). 